\title{
Views and practices of induced abortion among Australian Fellows and specialist trainees of the Royal Australian and New Zealand College of Obstetricians and Gynaecologists
}

\author{
Caroline M de Costa, Darren B Russell and Michael Carrette
}

\begin{abstract}
T nduced abortion has been increasingly practised by doctors in Australia since the late 1960s. ${ }^{1-3}$ Until the early 1990s, when medical abortion using mifepristone became available, induced abortion was performed using surgical techniques. However, mifepristone came under tight restrictions with the passage of the "Harradine amendment" to the Therapeutic Goods Act 1989 (Cwlth) in 1996. ${ }^{4,5}$ The overturning of the Harradine amendment in 2006 enabled mifepristone to be imported into and used in Australia ${ }^{6}$ but, to date, no drug company has applied to the Therapeutic Goods Administration to market the drug in Australia. About 80 medical practitioners are currently licensed to import and use mifepristone for the purpose of abortion in their own practices under the Authorised Prescriber legislation of the Therapeutic Goods Act. ${ }^{7}$

Although induced abortion forms part of the normal practice of most specialist obstetricians and gynaecologists in the United Kingdom, and many in the United States and Europe, this is thought to be less the case among Australian specialists. ${ }^{8-10}$ No formal survey of the abortion practice of Australian specialist obstetricians and gynaecologists has previously been undertaken, and there are few overseas studies in the literature..$^{8-12}$ Given the importance of specialist input into women's reproductive health, we conducted a survey of the opinions on and practice of abortion among Australian specialist obstetricians and gynaecologists.
\end{abstract}

\section{METHODS}

An electronic survey of Australian Fellows and specialist trainees of the Royal Australian and New Zealand College of Obstetricians and Gynaecologists (RANZCOG) was conducted between 23 June and 31 July 2009. Fellows are fully qualified and accredited specialist obstetricians and gynaecologists, and specialist trainees include all those registered with the RANZCOG as pursuing the requirements for Fellowship. Ethics approval for the study was obtained from the human research ethics committees of Cairns Base Hospital and James Cook University.

\section{ABSTRACT}

Objective: To determine the opinions and current practice of obstetricians and gynaecologists and trainees in the specialty with regard to induced abortion.

Design, setting and participants: A voluntary, anonymous survey of Australian Fellows and specialist trainees of the Royal Australian and New Zealand College of Obstetricians and Gynaecologists was conducted between 23 June and 31 July 2009 using an email invitation to proceed to an online questionnaire.

Main outcome measures: Attitudes to abortion; self-reported usual practice of induced abortion.

Results: Of 1498 Fellows and trainees invited to complete the questionnaire, 740 (49\%) did so. Of these respondents, 632 (85\%) stated that they did not hold religious or conscientious views that would make them totally opposed to abortion; 463 of these (73\%) reported performing abortion as part of their personal practice, with 204 (44\%) doing so only for severe fetal abnormality or serious maternal medical conditions. 108 respondents reported holding views that made them totally opposed to abortion - 60 (56\%) opposed it in any situation at all and $48(44 \%)$ opposed it with limited exceptions. Of those opposed, 34 (32\%) added comment that they perform abortion for severe fetal abnormality or serious maternal medical conditions, and a further 17 (16\%) commented that they refer women requesting abortion in these circumstances to colleagues. Of the respondents not opposed to abortion, $89 \%$ supported the availability of induced abortion within the public health system, and half felt that national availability of mifepristone would modify their practice of induced abortion.

Conclusions: There was broad support among responding specialist obstetricians and gynaecologists and trainees for the availability of induced abortion in Australia. This study highlights the difficulties of accurately reporting a wide range of views on a contentious issue.

MJA 2010; 193: 13-16

See also pages 9, 26

In February 2009, a questionnaire developed as a pilot project was sent to 16 Fellows of the RANZCOG, including four who stated their opposition to induced abortion. Some questions were subsequently reworded to assure recipients who held views opposed to abortion that we respected their views and appreciate that abortion is a sensitive issue for some Australians. In the refined questionnaire, such recipients were invited to note their views as well as some demographic details and comments, and to exit the survey without completing the five questions about abortion practice. Alternatively, they could choose not to participate. The refined questionnaire was then sent to the Continuing Professional Development Committee of the RANZCOG, who gave approval for the study.
The term "induced abortion" was used to cover termination of pregnancy using either surgical or medical methods as defined in the guidelines for induced abortion of the Royal College of Obstetricians and Gynaecologists in the UK. ${ }^{8}$ "Early" abortion was defined as up to and including 13 weeks of pregnancy; abortion up to this gestation is generally performed by surgical methods in current Australian practice. "Late" abortion was defined as abortion after 13 weeks' gestation; in Australia, the majority of abortions at gestations greater than 13 weeks are performed by medical methods.

Practising Australian Fellows of the RANZCOG who had supplied the College with an email address (1283/1361; 94.3\%) and all 435 Australian trainees (who are required to supply an email address for registration) were sent an email outlining 
1 Flow diagram of participation of Australian Fellows and specialist trainees of the RANZCOG in the survey

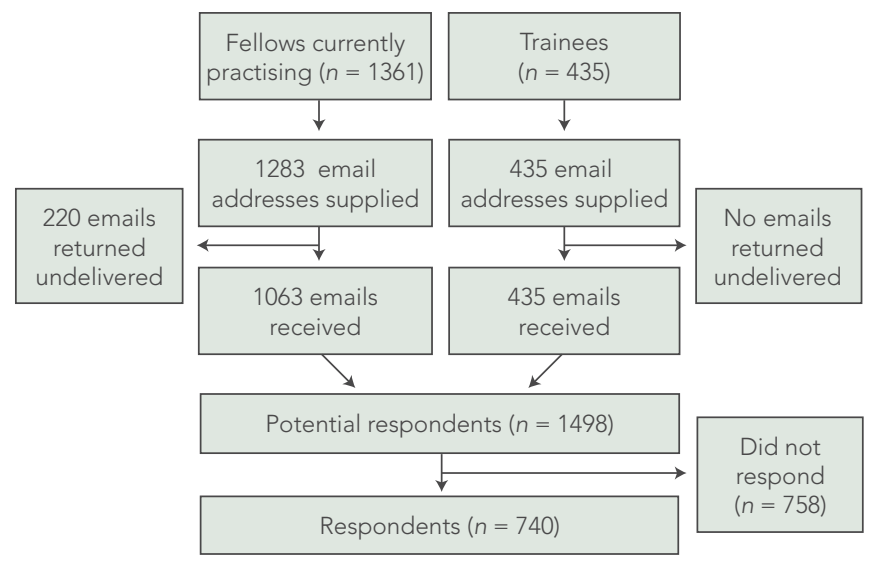

RANZCOG $=$ Royal Australian and New Zealand College of Obstetricians and Gynaecologists.

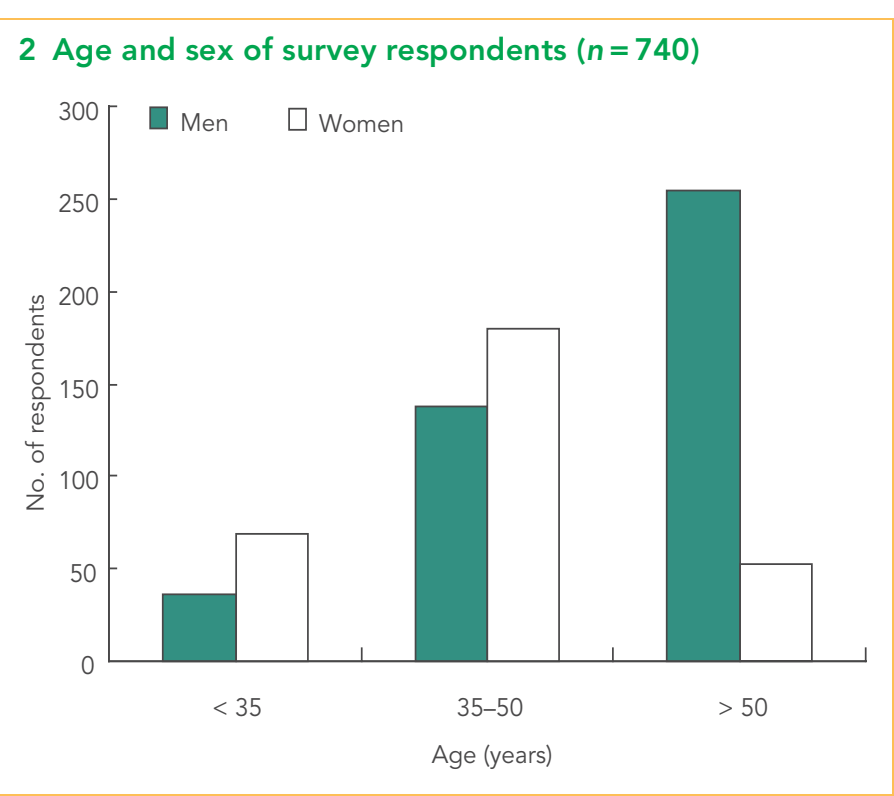

the purpose of the survey and inviting them to participate by clicking on a link which enabled them (on one occasion only) to anonymously complete the questionnaire (Box 1). A reminder email was sent 3 weeks later, inviting those who had not yet completed the survey to do so.

\section{RESULTS}

A total of 220 emails were returned from Fellows as undeliverable, leaving 1498 potential respondents (Box 1). From these, 740 responses were received (response rate of $49.4 \%$ for those successfully emailed). There were 583 Fellows and 142 trainees, and 15 did not identify as either. Age groups and sex of respondents are shown in Box 2 .

In describing their practice, 631 respondents $(85.3 \%)$ selected general obstetrics and gynaecology either in combination or alone, or maternal-fetal medicine; 99 (13.4\%) selected other subspecialties; and 10 (1.4\%) did not answer this question. When asked about their practice within the public and private systems, $333(45.0 \%)$ stated that they worked in both sectors, $287(38.8 \%)$ in only the public sector, and 106 (14.3\%) in only private practice; 14 (1.9\%) did not answer the question.

All 740 respondents answered the question about holding religious or conscientious views that would make them totally opposed to abortion: 108 (14.6\%) reported holding such views, and $632(85.4 \%)$ said they did not. Sixty (55.6\%) of the respondents who said they held views that would make them totally opposed to abortion indi- cated this was "in any situation at all", while for $48(44.4 \%)$ it was "with limited exceptions such as rape, incest, or where a minor is the patient". Many of those stating that they opposed abortion added comments to qualify their views and practices. Twelve of those who held views opposed to abortion in any situation at all nevertheless stated that they perform abortion for severe or lethal fetal abnormality or for serious maternal conditions, and another 17 refer women requesting abortion in these circumstances to colleagues. Twenty-two respondents who opposed abortion with limited exceptions stated that they would either perform abortion in cases of severe fetal abnormality or maternal medical conditions or refer women choosing abortion to a colleague. Fifty-seven respondents (52.8\% of those opposed; $7.7 \%$ overall) reported that they do not involve themselves at all in counselling or performing abortion.

Questions 5 to 9, regarding practice of induced abortion, were answered only by the 632 respondents who stated that they did not hold views that would make them totally opposed to abortion, and some chose not to answer one or more questions. Fivehundred and seventeen respondents (81.8\% of those not opposed) believed that the provision of induced abortion should be part of general obstetric and gynaecological practice (Box 3). Of these 517 respondents, 505 (97.7\%) stated that the practice of abortion should be part of the curriculum for RANZCOG trainees. Five hundred and sixty $(88.6 \%)$ of those not holding views making them totally opposed to abortion believed abortion should be available in the public health system throughout Australia. However, some of these respondents commented that the currently oversubscribed public operating lists should not be used for surgical abortions, and that these should be provided in dedicated clinics within the public system, as in the UK.

Details of abortion practice are shown in Box 3. Abortion formed part of the usual practice of $463(73.3 \%)$ of those not opposed to abortion. Notably, 204 respondents reported that they perform abortion only for severe fetal abnormality or serious maternal medical conditions - this corresponds to $44.1 \%$ of those who stated that they do perform abortions, and to $32.3 \%$ of those not opposed to abortion. The proportions of respondents who reported performing abortions for public and private patients were consistent with the numbers who reported practising in these sectors. Seventeen respondents stated that they were willing to perform abortions but did not do so because of limited hospital access. The questionnaire design did not allow us to determine the total number of respondents who do not currently perform abortion purely because of their practice circumstances. Fifteen others said that they practised in small communities and, although they did not hold views making them totally opposed to abortion, they did not want to become "the abortion doctor" in such a centre, partly because of the increased workload and partly because of possible social stigma for themselves or their families. Several respondents strongly made the point that 
3 Responses to survey questions 5-7 from respondents who stated they did not hold religious or conscientious views that would make them totally opposed to abortion $(n=632)$

\begin{tabular}{|c|c|c|c|c|}
\hline No. & Question & Yes & No & $\begin{array}{l}\text { Did not } \\
\text { answer }\end{array}$ \\
\hline \multirow[t]{2}{*}{5} & $\begin{array}{l}\text { Should the provision of induced abortion be part of } \\
\text { general obstetric and gynaecological practice? }\end{array}$ & $517(81.8 \%)$ & $107(16.9 \%)$ & $8(1.3 \%)$ \\
\hline & $\begin{array}{l}\text { If yes, should the practice of abortion be part of } \\
\text { the curriculum for MRANZCOG and DRANZCOG } \\
\text { candidates? }\end{array}$ & 505 (97.7\%) & $2(0.4 \%)$ & $10(1.9 \%)$ \\
\hline 6 & $\begin{array}{l}\text { Should induced abortion be available through the } \\
\text { public health systems of all states and territories? }\end{array}$ & $560(88.6 \%)$ & $49(7.8 \%)$ & $23(3.6 \%)$ \\
\hline \multirow[t]{12}{*}{7} & $\begin{array}{l}\text { Do you perform abortion, medical or surgical, as } \\
\text { part of your usual practice (even if infrequently)? }\end{array}$ & $463(73.3 \%)$ & $158(25.0 \%)$ & $11(1.7 \%)$ \\
\hline & If yes, please tick the relevant boxes & & & \\
\hline & (a) Early abortion ( $\leqslant 13$ weeks' gestation) & $214(46.2 \%)$ & & \\
\hline & (b) Late abortion (> 13 weeks' gestation) & $112(24.2 \%)$ & & \\
\hline & (c) Both early and late abortion & $137(29.6 \%)$ & & \\
\hline & (d) Medical abortion & $127(27.4 \%)$ & & \\
\hline & (e) Surgical abortion & $214(46.2 \%)$ & & \\
\hline & (f) Both medical and surgical abortion & $122(26.3 \%)$ & & \\
\hline & (g) For private patients only & $105(22.7 \%)$ & & \\
\hline & (h) For public patients only & $144(31.1 \%)$ & & \\
\hline & (i) For both private and public patients & $214(46.2 \%)$ & & \\
\hline & $\begin{array}{l}\text { (j) Only in cases of severe fetal abnormality or } \\
\text { major maternal medical conditions }\end{array}$ & $204(44.1 \%)$ & & \\
\hline
\end{tabular}

MRANZCOG = Member of the Royal Australian and New Zealand College of Obstetricians and Gynaecologists. DRANZCOG = Diploma of the Royal Australian and New Zealand College of Obstetricians and Gynaecologists.

they would not accept fees for performing abortion, including one who wrote, "I donate the fee to charity so that I feel I am doing a needed procedure".

Three hundred and thirty respondents (52.2\% of those who did not hold views that would make them totally opposed to abortion) said they counselled women regarding the options for unplanned pregnancy but referred women choosing abortion elsewhere. Of these, 194 (58.8\%) referred for both early and late abortion, 30 (9.1\%) for late abortion only, and 106 (32.1\%) for early abortion only. Among those who answered yes to this question were some who perform abortion themselves in some circumstances, and refer in others. The reasons given for this included ready access to local, dedicated early abortion services; lack of hospital access for late procedures; and a personal decision to perform abortion only for fetal abnormality or severe maternal conditions.

In answer to the question "Would availability of mifepristone nationally alter your practice of induced abortion?", 319 (50.5\% of those not opposed to abortion) said it would and 289 (45.7\%) said it would not. Comments from those who indicated it would change their practice included: "I would do less surgical terminations" and "It would formalise an early abortion service in public hospitals". Three respondents commented that they had used the drug in Australia, and seven had used it overseas; all reported positive experiences. Two others had also used it overseas but would not change their Australian practice if it were available. One wrote, "I find surgical abortion perfectly adequate for my practice, and based on my experiences in the UK feel that mifepristone abortions are extremely unpleasant". Another aspect mentioned by a few respondents was, "It would allow me not to be intimately involved with the termination. I am an atheist but not morally comfortable surgically terminating a viable pregnancy unless there are significant fetal abnormalities". A similar point of view was expressed by other respondents - for example, "I do not think it necessarily a double standard to believe abortion should be freely and safely available and yet not be prepared to perform one".

\section{DISCUSSION}

The majority of practising doctors who responded to our survey regard abortion as a valid and important part of their professional practice, and many of them are active in informing women about choices and service provision even when they are personally opposed to the practice of abortion.

This electronic survey elicited responses from only $49.4 \%$ of those successfully emailed, so that the views of more than half of the Fellows and trainees of the RANZCOG remain unknown. However, the demographics of the respondents were consistent with the age, sex and practice patterns of the College Fellowship as reported in the most recent RANZCOG workforce survey. ${ }^{13}$ This study is only the second electronic survey emailed to RANZCOG Fellows and trainees using the College database. The first elicited a response rate of only $16 \%,{ }^{14}$ so increasing familiarity with the process might lead to higher response rates to future surveys. Initially, a number of email recipients expressed concerns about the legitimacy of a survey dealing with abortion and contacted us directly. We attempted to allay these concerns by sending the second (reminder) email with electronic signatures to all email addresses, and by giving verbal assurances to those who contacted us.

We experienced considerable difficulty in wording questions to cover all possible views and practices of abortion, and this was reflected in a number of comments from respondents, including, "I think your questions are too simplistic as there are many shades to the issues" and "Some of the questions are too black and white - this subject has grey areas too".

As a result of the pilot survey and to respect the views of those for whom abortion is a sensitive issue, we directed respondents who declared themselves opposed to abortion to exit after Question 4. However, two respondents in this totally opposed group made the valid criticism that this biased the answers to Questions 5 to 9 . One commented that, "I would counsel women about their options, but, with the exception of lethal fetal abnormality or lifethreatening maternal illness, refuse to perform abortions or refer these women elsewhere for termination of pregnancy. I believe your questionnaire is biased against 
pro-life doctors, and ... doctors with religious or ethical objections to abortion ... even completing the questionnaire." In reporting our results, we have therefore made clear that all the respondents to Questions 5 to 9 had declared they did not hold views that would make them totally opposed to abortion. The pilot study also led to the decision to include the word "totally" when asking about views opposed to abortion, as without it the question was thought to be too vague.

Twelve respondents noted what they saw as a failure of the questionnaire to separate "medically indicated" from "social" termination. One wrote: "This survey is unsatisfactory as it does not clearly distinguish between social and non-social abortions". However, through responses to the pilot survey it had become clear that the terms "medically indicated" and "social" may often overlap in individual cases. While abortion for lethal fetal anomalies or serious maternal illness would be widely agreed to be purely medically indicated, abortion for many other reasons (eg, after the diagnosis of trisomy 21 in the fetus, or for very young teenage women) is arguably offered for both social and medical indications. We therefore chose to distinguish only between "early" (up to 13 weeks' gestation) abortion, which would include most "social" indications, and "late" (after 13 weeks' gestation) abortion, which in Australian practice is largely for medical indications - either fetal abnormality or severe maternal conditions. The majority of respondents who commented seemed to accept this distinction. In addition, the use of the word social when applied to induced abortions is not reflected in the literature surrounding this issue, and can also be seen to be judgemental.

There are few overseas studies comparable to ours. A 1989 UK survey of 396 consultant gynaecologists showed that $73 \%$ "agreed with a woman's right to choose" only slightly lower than among the general population. Abortions up to 12 weeks' gestation were performed by $75 \%$ of respondents, but $20 \%$ of these did not do so after 12 weeks' gestation, and only $10 \%$ would do so after 20 weeks (this survey antedated the wide availability of medical abortion in the UK). ${ }^{9}$

Among Australian RANZCOG specialists and trainees who responded to our questionnaire, there was a wide spectrum of views not easily captured by a limited number of precise questions. Nevertheless, this study provides new information about the views on a controversial issue of a group of practising doctors who have a major influence on women's health practice and policies. The impact of the views of specialist obstetricians and gynaecologists on women's access to abortion across Australia needs further study.

\section{ACKNOWLEDGEMENTS}

We are grateful to all our colleagues who took the time to complete the survey. We also thank Ms Hilary Waugh and the staff of the Teaching and Development Unit, James Cook University, for their invaluable assistance in conducting the survey.

\section{COMPETING INTERESTS}

None identified.

\section{AUTHOR DETAILS}

Caroline M de Costa, PhD, FRANZCOG, FRCOG, Professor ${ }^{1}$

Darren B Russell, FRACGP, DipVen, FAChSHM, Director, Sexual Health Clinic ${ }^{2}$

Michael Carrette, MB BCh, FRANZCOG,

Obstetrician and Gynaecologist ${ }^{3}$

1 Department of Obstetrics and Gynaecology, James Cook University School of Medicine,

Cairns Campus, Cairns, QLD.

2 Cairns Base Hospital, Cairns, QLD.

3 Cairns Private Hospital, Cairns, QLD.

Correspondence: caroline.decosta@jcu.edu.au

\section{REFERENCES}

1 Victorian Law Reform Commission. Law of abortion: final report. Melbourne: Victorian Government Printer, 2008: 144-147.
2 de Crespigny LJ, Savulescu J. Abortion: time to clarify Australia's confusing laws. Med J Aust 2004; 181: 201-203.

3 Taskforce on Women and the Criminal Code. Women and the criminal code [report]. Brisbane: Queensland Government, 2002. http:// www.women.qld.gov.au/resources/criminalcode/ (accessed Aug 2009).

4 Healy DL, Fraser H. The anti-progesterones are coming - induced menses, abortion, and labour? BMJ 1985; 290: 580-581.

5 Hansard, Australian Senate. Debates. Therapeutic Goods Amendment Bill 1996 (No. 2). 8 May 1996. http://www.aph.gov.au/hansard/senate/dailys/ds080596.pdf (accessed Oct 2009).

6 Zinn C. Health minister is stripped of his right to veto use of abortion pill. BMJ 2006; 332: 441.

7 Therapeutic Goods Administration. Access to unapproved therapeutic goods - authorised prescribers. Canberra: TGA, 2004. http:// www.tga.gov.au/docs/html/authpres.htm\#ap (accessed Sep 2009).

8 Royal College of Obstetricians and Gynaecologists Guideline Development Group. The care of women requesting induced abortion. Evidence-based clinical guideline no. 7. London: RCOG, 2004.

9 Savage W, Francome C. Gynaecologists' attitudes to abortion. Lancet 1989; 2: 1323-1324.

10 Sparrow MJ. A woman's choice. Aust N Z J Obstet Gynaecol 2004; 44: 88-92.

11 Francome C, Savage WD. Gynaecologists' abortion practice. Br J Obstet Gynaecol 1992; 99: 153-157.

12 American Congress of Obstetricians and Gynecologists. ACOG patient education: special precedures. Induced abortion. http:// www.acog.org/publications/patient_education/bp043.cfm (accessed Aug 2009).

13 Bell R. The 2003 RANZCOG workforce survey. O\&G Magazine 2003; 5: 174-178.

14 Ellwood D. What do our readers think of ANZJOG? Aust N Z J Obstet Gynaecol 2009; 49: 343.

(Received 4 Oct 2009, accepted 18 Feb 2010) 